\title{
Comparative Evaluation of Sealing Ability of ProRoot MTA, Biodentine, and Bone Cement in the Repair of Furcation Perforation - An In Vitro Study
}

\author{
Thota Murali Mohan, Kakollu Sudha, Chinthamreddy Shoba, Tammineedi Sravanthi, \\ Bhupathi Sravanthi Yadav, Ediga Sandhya Rani \\ Department of Conservative Dentistry and Endodontics, Government Dental College and Hospital, Vijayawada, Andhra Pradesh, India
}

Email for correspondence: sudhakishan996@gmail.com

\begin{abstract}
Context: Furcal perforation is a common occurrence during endodontic treatment. Prompt intervention and use of proper repair materials are very important to improve the prognosis of involved tooth. Material qualities are also determining factor of success. Search for newer materials that are easy to manipulate, cost effective with better physical and biological properties is a never-ending process. Objective: The aim of the present in vitro study was to evaluate the sealing ability of ProRoot MTA, biodentine, and bone cement as furcation repair materials in molar teeth using dye penetration method analyzed under the stereomicroscope. Materials and Methods: A total of 45 recently extracted mandibular molars with non-fused well-developed roots were collected and intentional furcation perforations were made with a bur and perforations were treated with ProRoot MTA, biodentine, and bone cement. These specimens were then immersed in Rhodamine B dye. After their removal, dye penetration was evaluated after longitudinal sectioning of the teeth under the stereomicroscope. Results: The results showed that furcation perforation repaired with biodentine showed decrease in microleakage compared with that of ProRoot MTA and bone cement. However, there was no statistically significant difference between the ProRoot MTA and biodentine. Conclusion: Biodentine is a promising material for furcation repair as it overcomes some of the disadvantages of ProRoot MTA such as long setting time and poor handling characteristics.
\end{abstract}

Key words: Biodentine, bone cement, dye penetration, furcal perforation, ProRoot MTA

\section{INTRODUCTION}

Endodontic therapy plays a key role in maintaining the integrity of the natural dentition which is essential for full function and natural esthetics. $^{[1]}$ In endodontic practice, procedural accidents are encountered frequently that will affect the prognosis of the root canal treatment. One of these procedural accidents is endodontic perforation. ${ }^{[2]}$

\section{Quick Response Code Article Info:}

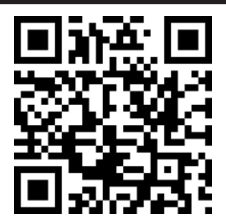

doi: 10.5866/2018.10.10176

Received: 25-09-2018

Revised: $30-10-2018$

Accepted: $24-11-2018$

Available Online: 05-01-2019, (www.

nacd.in)@ NAD, 2019 - All rights reserved
According to Ingle, an endodontic perforation is an artificial opening in the tooth or its root created by the clinician during entry to the canal system or by a biological event such as pathological resorption or caries results in a communication between the root canal and the periodontal tissue. Except for resorptive defects or caries, furcation or root perforations are iatrogenic in nature and are the key causes of endodontic failure. Root perforations are reported as the second greatest cause of failure accounting for $9.62 \%$ of all unsuccessful cases. A furcation perforation refers to a midcurvature opening into the periodontal space and is the worst possible outcome in root canal treatment.

Favorable healing of periodontal tissue has been reported to occur when defects were closed as compared to those left open. ${ }^{[3]}$ The choice of sealing material is a crucial factor that influences the outcome of treatment. ${ }^{[4]}$ 
According to Ingle, ideal requirements of perforation repair material are as follows:

- Provide an adequate seal.

- Be biocompatible.

- Not affected by blood contamination.

- Bactericidal.

- Should induce bone formation and healing.

- Radiopaque.

- Induce mineralization.

- Cementogenesis.

- Easy in manipulation and placement.

The most commonly used repair materials are amalgam, resin-modified glass ionomer cement, calcium hydroxide, glass ionomer cement, composite resin, and ProRoot MTA. ProRoot MTA is a biomaterial that has been investigated for endodontic applications since the early 1990s. Despite its many advantages, MTA has some drawbacks such as a long setting time and discoloration potential, among others. ${ }^{[5,6]}$ Hence, efforts have been made to overcome these shortcomings, new calcium silicate-based bioactive restorative cement has been developed, namely biodentine. Advantages of this material are short setting time, high compressive and flexural strength, and color stability along with ease of manipulation. ${ }^{[7,8]}$

Bone cement is a potentially new repair material that has been investigated in dentistry recently, although it has been used in orthopedic surgery for the past 40 years, especially for the fixation of implants such as artificial hip joints with living bone. ${ }^{[9]}$ The purpose of the present study was to evaluate the sealing ability of ProRoot MTA, biodentine, and bone cement as furcation repair materials in molar teeth using dye penetration method analyzed under the stereomicroscope.

\section{MATERIALS AND METHODS}

A total of 45 extracted human mandibular molar teeth with non-fused and well-developed roots, no caries or cracks were used in this study. Teeth were disinfected in 5\% sodium hypochlorite solution for 30 min and stored in physiological saline. A standard endodontic access opening was prepared in all the teeth. Teeth were then decoronated 3 millimeters above cementoenamel junction using diamond disc under continuous water cooling. Similarly, roots were amputated $3 \mathrm{~mm}$ below the furcation. Sticky wax was placed over the orifice of each canal and the sectioned root surface including the pulpal floor. Teeth were then coated with two layers of varnish and perforations made in the furcation area. To ensure each perforation was centered between the roots, an indelible black marker pen was used to mark the location of the perforation. A perforation of $1 \mathrm{~mm}$ diameter was made from the external surface of the tooth with number 2 round carbide bur (SS White, USA) mounted on high-speed handpiece with air water coolant. The chamber and perforation were then flushed with saline and air-dried specimens were randomly divided into three groups $(n=15)$ according to the perforation material used for furcal repair:

- Group A: ProRoot MTA group.

- Group B: Biodentine group.

- Group C: Bone cement group.

Each repair material was mixed according to the manufacturer's instructions and was packed into the perforation defect to the level of the pulpal chamber floor. The root was moistened with cotton pellet inertly to simulate the clinical situation during the repair process. After $24 \mathrm{~h}$, the access cavity was filled with composite resin. All teeth were placed in a thermocycling device for 2 days. Surfaces of the molars including access filling were covered completely with two successive layers of nail varnish except around the perforation area such that dye would penetrate only through the perforation area. The specimen was placed in $0.5 \%$ Rhodamine B dye solution for $24 \mathrm{~h}$ and then rinsed under tap water for $30 \mathrm{~min}$. Then, teeth were split buccolingually with a diamond disc in a high-speed lathe. In each section, the actual value of dye leakage was calculated from outer margins of perforation cavity to the level of pulpal floor. The maximum dye penetration along the buccal and lingual walls of either the mesial or distal section was recorded using stereomicroscope $(\times 10)$ as in Figures 1-3. These various values were then subjected to statistical analysis.

\section{RESULTS}

SPSS (Version 16) and Microsoft Excel software were used to carry out the statistical analysis of data. Mean and standard deviations were calculated. Comparison between the groups was done using ANOVA test and pairwise comparison was done using Tukey post hoc test [Table 1]. $P>0.05$ was considered statistically significant. Results demonstrated that furcation perforation repaired with biodentine showed decreased microleakage when compared with that of ProRoot MTA and bone cement as shown in Table 1. However, there was no statistically significant difference 


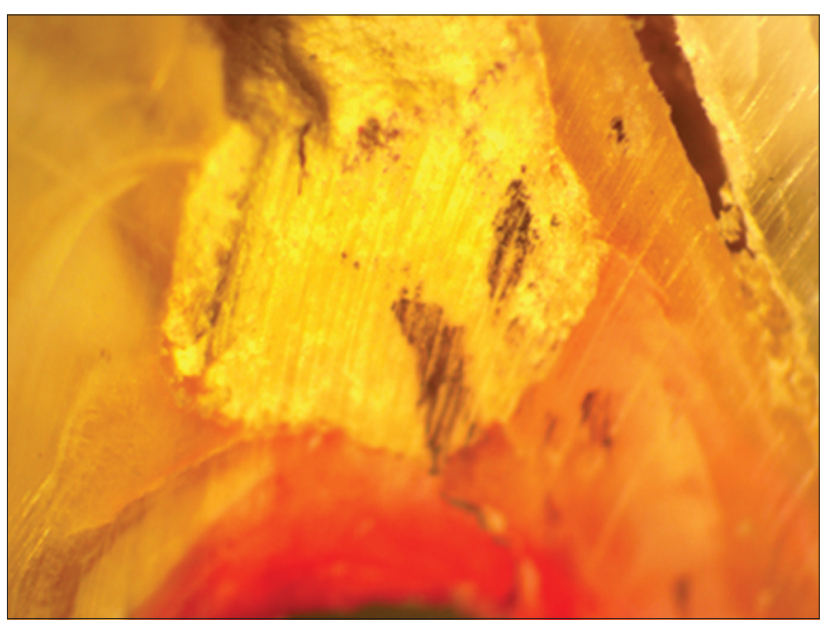

Figure 1: Stereomicroscopic picture showing dye penetration of ProRoot MTA

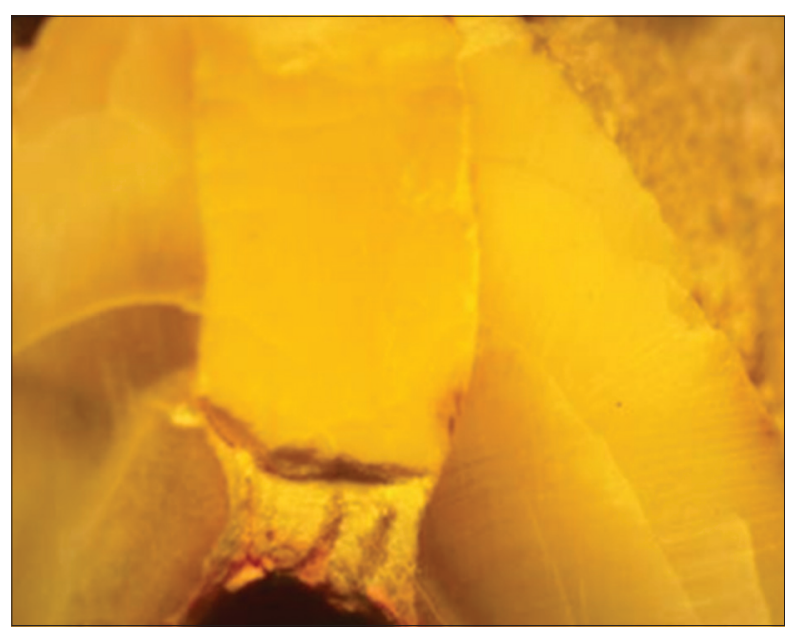

Figure 2: Stereomicroscopic picture showing dye penetration of biodentine

between the ProRoot MTA and biodentine and statistically significant difference between ProRoot MTA and bone cement, and biodentine and bone cement as shown in Table 2.

\section{DISCUSSION}

The principal goal of endodontic therapy is to remove microbes and seal the root canal system effectively. Inadvertent perforation interferes with this goal due to damage to the periodontal attachment apparatus and subsequent bacterial proliferation. Perforations can be successfully managed with the use of a non-surgical coronal approach by immediate placement of the reparative material in the perforation to prevent a bacterial infection. ${ }^{[10]}$

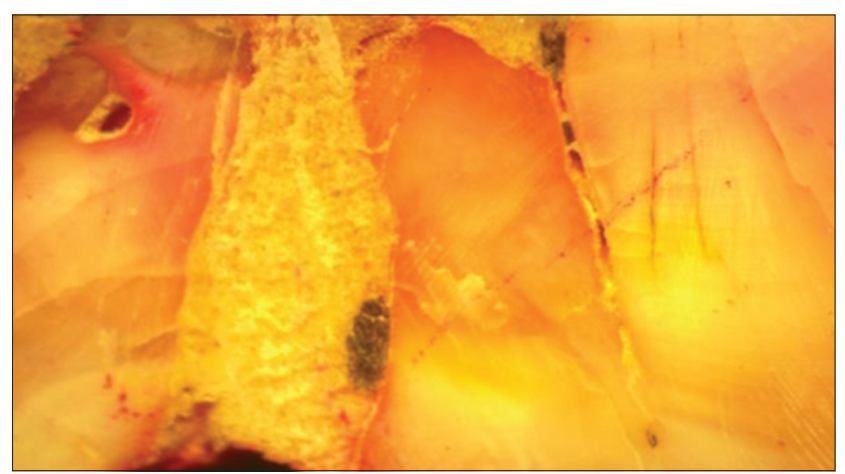

Figure 3: Stereomicroscopic picture showing dye penetration of bone cement

Long-term success of a perforation repair is related to several factors among which the foremost is the biocompatibility of the material and ability of repair material to provide an adequate seal. ${ }^{[11-15]}$

Therefore, the present study was conducted to compare the sealing ability of ProRoot MTA, biodentine, and bone cement when used to repair perforations in the furcation area. In the present study, biodentine (Group B) showed decrease in microleakage when compared with that of ProRoot MTA (Group A) and bone cement (Group C).

Biodentine is a bioactive dentine substitute specifically designed as a "dentine replacement" material. ${ }^{[16]}$ The powder component of the material consists of tricalcium silicate, dicalcium silicate, calcium carbonate and oxide filler, iron oxide shade, and zirconium oxide, respectively, whereas zirconium oxide serves as a radio-opacifier. The liquid, on the other hand, contains calcium chloride as an accelerator and a hydrosoluble polymer that serves as a water reducing agent. The setting period of the material is as short as 9-12 min. The presence of setting accelerator in biodentine results in faster setting, thereby improving its handling properties and strength. This is an advantage over ProRoot MTA since a delayed setting time studied by Torabinejad et al. leads to an increased risk of partial material loss and alteration of the interface during the finishing phase of the procedure. Therefore, biodentine has a great improvement compared to ProRoot MTA in terms of setting time. ${ }^{[17-20]}$

ProRoot MTA is a mixture of a refined Portland cement, bismuth oxide, and gypsum and is reported to contain trace amounts of $\mathrm{SiO}_{2}, \mathrm{CaO}, \mathrm{MgO}, \mathrm{K}_{2} \mathrm{SO}_{4}$, and $\mathrm{Na}_{2} \mathrm{SO}_{4}$. ProRoot MTA has been extensively used as perforation repair material due to its 
Table 1: Comparison of microleakage between the study groups

\begin{tabular}{|c|c|c|c|c|c|c|}
\hline \multirow[t]{2}{*}{ Study groups } & \multirow[t]{2}{*}{$\mathbf{N}$} & \multirow[t]{2}{*}{ Mean \pm standard deviation } & \multirow[t]{2}{*}{ Minimum } & \multirow[t]{2}{*}{ Maximum } & \multicolumn{2}{|c|}{ ANOVA } \\
\hline & & & & & $\mathbf{F}$ & $P$-value \\
\hline Group A & 15 & $1.15 \pm 0.08$ & 1.01 & 1.31 & 253.40 & $<0.001^{*}$ \\
\hline Group B & 15 & $1.05 \pm 0.16$ & 0.81 & 1.30 & & \\
\hline Group C & 15 & $2.22 \pm 0.21$ & 1.89 & 2.63 & & \\
\hline
\end{tabular}

$* P<0.05$ statistically significant, $P>0.05$, NS: Non-significant

Table 2: Pairwise comparison of dye penetration between the study groups

\begin{tabular}{llccccc} 
(I) Group & (J) Group & Mean difference (I-J) & Standard error & P-value & \multicolumn{2}{c}{ 95\% confidence interval } \\
\cline { 5 - 7 } & & & & & Lower bound & Upper bound \\
\hline Group A & Group B & 0.10 & 0.06 & $0.20(\mathrm{NS})$ & -0.04 & 0.24 \\
& Group C & -1.08 & 0.06 & $<0.001^{*}$ & -1.22 & -0.94 \\
Group B & Group C & -1.18 & 0.06 & $<0.001^{*}$ & -1.32 & -1.04 \\
\hline
\end{tabular}

Tukey post hoc test, $* P<0.05$ statistically significant, $P>0.05$, NS: Non-significant

reported favorable sealing ability, biocompatibility, and dentinogenic activity. ${ }^{[12]}$ However, it has long setting time along with sensitivity to excessive or deficient moisture which affects its properties in a detrimental way. ${ }^{[5,15]}$ Discoloration of teeth restored with white MTA still seems a problem in some clinical cases. ${ }^{[6]}$

The third material used in the study to repair furcation perforation was bone cement. Bone cement consists of polymethylmethacrylate and methyl methacrylate; the bone cement is said to exhibit low cytotoxicity and was found to be non-toxic in nature. It exhibits excellent biocompatibility, thus may allow for tissue reattachment. In addition, bone cement tolerates a moist environment very well. Blood contamination of bone cement resulted in a slight decrease in shear strength and no difference in mechanical penetration of the cement into the bone-bone cement interface. These characteristics potentially make it a suitable and desirable perforation repair material.

One of the problems of bone cement is the generation of high temperature during its polymerization, but Blinc et al. suggested that there was a negligible thermally induced effect of bone cement as mass of the cement used is small. ${ }^{[21]}$ Microleakage of bone cement was more when compared with ProRoot MTA and dentine may be due to polymerization shrinkage as it is acrylic-like material.

Many techniques including dyes (India ink and methylene blue), chemical tracers, radioactive isotopes, scanning electron microscopy, and electrical conductivity have been used to test the sealing properties of restorative materials both in vivo and in vitro. The dye penetration technique has long been used in endodontics due to its ease of performance, does not require sophisticated materials. ${ }^{[22,23]}$

In the present study, specimens were immersed in a $0.5 \%$ aqueous Rhodamine B dye. Rhodamine B is a water-soluble fluorescent dye which is easily detectable, even in a low concentration, moves freely along the interface, low toxicity and is stable in an aqueous environment, stable in varying $\mathrm{pH}$, non-destructive to the substrate, or material in contact. $^{[24,25]}$

Gutman, in his study on furcation region of permanent molars, had reported that patency and ability of the fluid to pass through accessory canals in furcation. Therefore, all teeth were painted with a coat of nail polish to prevent dye penetration into lateral and accessory canals, especially in the furcation area. All the materials used in this in vitro study were tested under similar conditions, and therefore, the material showing the least leakage may be the material of choice for clinical applications. ${ }^{[26]}$

\section{CONCLUSION}

Within the limitations of the present study, it can be concluded that both biodentine and MTA showed good sealing ability than bone cement when used as furcation repair material. Biodentine can be a promising material for furcation repair as it 
overcomes some of the disadvantages of MTA such as long setting time and poor handling characteristics.

\section{REFERENCES}

1. Jew RC, Weine FS, Keene JJ Jr., Smulson MH. A histologic evaluation of periodontal tissues adjacent to root perforations filled with cavit. Oral Surg Oral Med Oral Pathol 1982;54:124-35.

2. Kakani AK, Veeramachaneni C, Majeti C, Tummala M, Khiyani L. A review on perforation repair materials. J Clin Diagn Res 2015;9:ZE09-13.

3. Lantz B, Persson PA. Periodontal tissue reactions after root perforations in dog's teeth. A histologic study. Odontol Tidskr 1967;75:209-37.

4. Rafter M, Baker M, Alves M, Daniel J, Remeikis N Evaluation of healing with use of an internal matrix to repair furcation perforations. Int Endod J 2002;35:775-83.

5. Ding SJ, Kao CT, Shie MY, Hung C Jr., Huang TH. The physical and cytological properties of white MTA mixed with na2HPO4 as an accelerant. J Endod 2008;34:748-51.

6. Watts JD, Holt DM, Beeson TJ, Kirkpatrick TC, Rutledge RE. Effects of $\mathrm{pH}$ and mixing agents on the temporal setting of tooth-colored and gray mineral trioxide aggregate. J Endod 2007;33:970-3.

7. Grech L, Mallia B, Camilleri J. Investigation of the physical properties of tricalcium silicate cement-based root-end filling materials. Dent Mater 2013;29:e20-8.

8. Vallés M, Mercadé M, Duran-Sindreu F, Bourdelande JL, Roig M. Influence of light and oxygen on the color stability of five calcium silicate-based materials. J Endod 2013;39:525-8.

9. Miyazaki T, Ohtsuki C, Kyomoto M, Tanihara M, Mori A, Kuramoto K, et al. Bioactive PMMA bone cement prepared by modification with methacryloxypropyltrimethoxysilane and calcium chloride. J Biomed Mater Res A 2003;67:1417-23.

10. Friedman S. Considerations and concepts of case selection in the management of post-treatment endodontic disease (treatment failure). Endod Topics 2002;1:54-78.

11. Mir A, Misgar OH, Farooq R. Comparison of sealing ability of biodentine, bioactive bone cement and MTA as furcation repair materials. IOSR JDMS 2017;16:4.

12. Sarkar NK, Caicedo R, Ritwik P, Moiseyeva R, Kawashima I. Physicochemical basis of the biologic properties of mineral trioxide aggregate. J Endod 2005;31:97-100.

13. Camilleri J, Montesin FE, Brady K, Sweeney R, Curtis RV,
Ford TR. The constitution of mineral trioxide aggregate. Dent Mater 2005;21:297-303.

14. Dammaschke T, Gerth HU, Züchner H, Schäfer E. Chemical and physical surface and bulk material characterization of white proRoot MTA and two Portland cements. Dent Mater 2005;21:731-8.

15. Walker MP, Diliberto A, Lee C. Effect of setting conditions on mineral trioxide aggregate flexural strength. J Endod 2006;32:334-6

16. Han L, Okiji T. Uptake of calcium and silicon released from calcium silicate-based endodontic materials into root canal dentine. Int Endod J 2011;44:1081-7.

17. Kaur M, Singh H, Dhillon JS, Batra M, Saini M. MTA versus biodentine: Review of literature with a comparative analysis. J Clin Diagn Res 2017;11:ZG01-5.

18. Harper EJ. Bioactive bone cements. Proc Inst Mech Eng H 1998;212:113-20

19. Shinzato S, Kobayashi M, Mousa WF, Kamimura M, Neo M, Kitamura Y, et al. Bioactive polymethyl methacrylate-based bone cement: Comparison of glass beads, apatite- and wollastonite-containing glass-ceramic, and hydroxyapatite fillers on mechanical and biological properties. J Biomed Mater Res 2000;51:258-72.

20. Lewis G. Properties of acrylic bone cement: State of the art review. J Biomed Mater Res 1997;38:155-82.

21. Blinc A, Bozic M, Vengust R, Stegnar M. Methyl-methacrylate bone cement surface does not promote platelet aggregation or plasma coagulation in vitro. Thromb Res 2004;114:179-84.

22. Madfa AA, Al-Sanabani FA, Al-Qudami Al-Kudami NH. Endodontic repair filling materials: A review article. $\mathrm{Br} \mathrm{J}$ Med Med Res 2014;4:3059-79.

23. Attavar SH. Comparative evaluation of the sealing ability of dentine and MTA in furcation repair - An in vitro stereomicroscopic study. Int J Curr Res 2015;7:16984-8.

24. Shah PU, Mane DR, Angadi PV, Hallikerimath SR, Kale AD. Efficacy of stereomicroscope as an aid to histopathological diagnosis. J Oral Maxillofac Pathol 2014;18:356-60.

25. D'Alpino PH, Pereira JC, Svizero NR, Rueggeberg FA, Pashley DH. Use of fluorescent compounds in assessing bonded resin-based restorations: A literature review. J Dent 2006;34:623-34.

26. Chohayeb AA, Chow LC, Tsaknis PJ. Evaluation of calcium phosphate as a root canal sealer-filler material. J Endod 1987;13:384-7. 